2 or 3 per cent., is allowed to mix with the nitrous oxid, and as the anesthesia progresses the oxygen may be increased to 6 or 8 per cent. or sufficient to prevent cyanosis or asphyxia. When the patient is profoundly under the anesthetic the nitrous oxid may be replaced by ether vapor and the oxygen by air. In all these changes the relative percentage of the two gases being used are under the immediate control of the anesthetist, who has merely to change the pointer on the face-mask which indicates the percentage of the two gases.

The water in which the two gas-tanks float is prefer. ably made warm. This warms and moistens the anesthetic vapors prior to their inhalation, which is a great advantage in the administration of ether to prevent the bronchial eatarrh and pneumonia which too often fol-

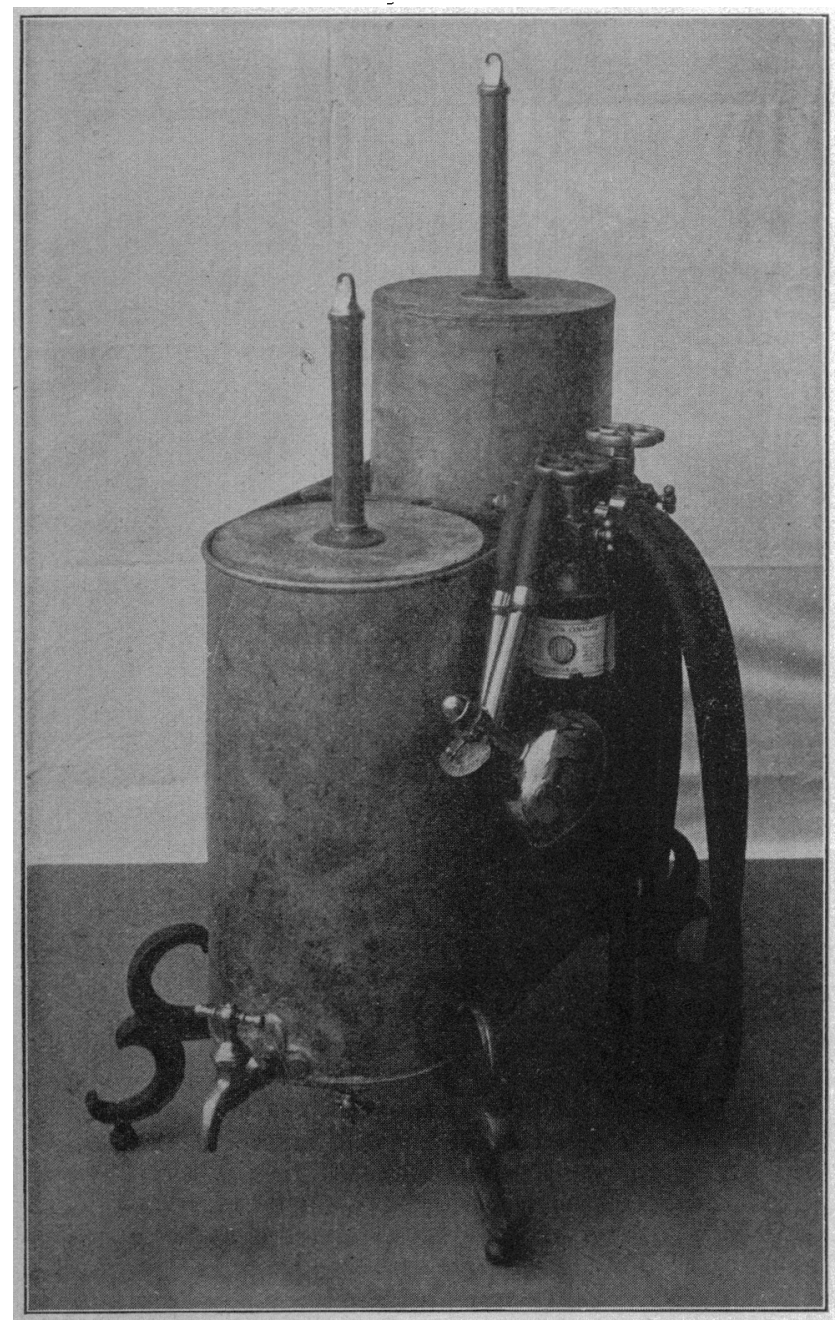

Fig. 2.-Apparatus for administering nitrous oxid and oxygen in definite proportions.

low the administration of this agent by the drop method. The continuous evaporation of the ether has a chilling effect on the vapor, and this can be overcome only by warming the ether vapor rather than the ether fluid. I fill a gasometer with water at $130 \mathrm{~F}$. and this remains sufficiently warm for some hours afterward.

In administering ether, compressed air is used to vaporize the ether for one gasometer and to keep the other gasometer filled with air. The compressed air may be supplied from any of the usual sources. Its entrance to the gas tanks is regulated automatically and it $i$ : allowed to enter in sufficient cuantities to keep both gasometers filled. The automatic check-valves are regulated by the rise and fall of the gasometers.

A simpler apparatus, Figure 2, has been made without the ether attachment which is used for administej.. ing nitrous oxid and oxygen. No compressed air is required for this.

The advantages claimed for the apparatus are the following:

1. It delivers the two gases into the mask with abso. lute uniformity of pressure and mixed in definite percentages. The accuracy of these percentages can be accurately tested at all times by shutting off the air supply and noting the relative fall in the two gas tanks during a given time.

2 . The relative proportion of the two gases is conveniently under the control of the anesthetist, the regulating device being on the mask. The proportion of the two gases can be instantly changed to meet the requirements of the patient.

3. In administering ether, the apparatus requires no attention except the introduction of a fresh supply of ether once in an hour or so. This may be done while the anesthesia is progressing, as the ether botttle can be cut off from communication with the gas tanks by a valve. There is sufficient gas in the tanks to continue the anesthesia until the connection with the ether bottle is restored.

4. Perhaps the greatest advantage of this apparatus over all other forms of anesthetic apparatus which mix gas definitely is the use of warm water in the gasometer tanks, which warms and moistens the gases. This prepares the gases much better for reception by the bronchial tubes. Respiratory spasm is less likely to be excited and the bronchial complications which often follow ether administration are reduced to a minimum.

The new thing in this apparatus is the use of two gasometers with a mixing valve in the mask.

\section{ACCIDENTAL LABORATORY INFECTION WITH DIPHTHERIA BACILLUS}

\section{L. HOLM, M.D.}

Bacteriologist Michigan State Board of Health LANSING, MICH.

II istory.-On December 2 I received at the laboratory a very thin homeopathic vial containing a suspected diphtheritic membrane for examination. In attempting to remove the cork the vial was broken and a piece of glass was driven into my left index finger. The wound was allowed to bleed freely for sevcral minutes, then carefully cleansed with a 10 per cent. solution of formalin and closed with celloidin. The wound in the finger showed no sign of infection before the morning of the second day, when a grayish yellow border was observed around the margin. The wound was opened and found to contain sereral drops of thick grayish brown fluid, which on microscopic examination was found to consist largely of polymorphonuclear lealcocytes and some blood. Numerous $B$. diphtheria werc present, all of which were found inside the leucocytes, there being from two to five such leucocytes to the field, each cor: taining from ten to twenty bacilli.

Treatment.-The wound was again cleansed with 10 per cent. formalin, sealed with celloidin and 1000 units of diph. theria antitoxin were injected into the forearm. Smears and cultures from the wound taken on the following day were sterile and healing occurred in the usual time without further complications.

The membrane submitted was from the pharynx of a child and had been taken on the fourth day of the discase. Smear preparations from the membrane 
showed $B$. diphtherice in almost pure culture. The organisms were of the barred type, very large, with marked tendency to club formation. Cultures from this membrane on Loeffler serum at 35 degrees C., examined after seven hours, gave the solid type, and after twenty-four. hours the usual granular organisms. The direct smears from the infected finger showed small organisms of the solid type. Cultures from the infected finger at 35 degrees C. gave the solid type after seven hours, and after twenty-four hours the usual granular organisms, exactly as did the original membrane. 'This illustrated beautifully the possibility of morphologic variations in the same strain of organisms when infecting individuals under different conditions.

\section{INSTRUMENT FOR APPROXIMATION OF THF PALATINE PROCESSES IN CASES OH CONGENITAL CLEFT PALATE}

\author{
L. J. HAMMOND, M.D. \\ Surgeon, Methodist Episcopal Hospital \\ PIIILADELPHIA
}

The method advocated by Brophy for bringing the palatine processes in apposition as a preliminary to operative procedure for uniting the soft parts, and so successfully employed by him, has not in my hands been so satisfactory. Even when successful it is so at the expense of a great amount of mutilation of the parts and suffering of the individual. The one other method that has been more generally employed with instances of satisfactory results is that of having the mother encourage the inward growth of the cheeks and, consequently, the palatine processes by firmly compressing the cheeks on either side with the two hands at the same time. This method, of course, can only be successfully employed before ossification has caused fixation.

My repeated failures, therefore, with most of the devices heretofore employed in retaining the palatine processes in position have incited me to devise the comparatively simple instrument shown in the illustration. It is most efficient in all cases in which there is enough of the palatine processes present to be brought together. This can be done at once when the subject is under 5 or 6 months of age. After this period it can be officiently done by continuously increasing pressure, which should be continued over a period of four or six wecks.

The instrument consists of two lateral plates, semjoval, so as to conform to the shape of the lateral haives of the superior maxillary bone, fastened together in front by a hinge in order to prevent any play of the lateral half while being introduced. They are brought together by a central right and left screw which is so arranged as to bring together or separate the two lateral plates simultaneously. Sufficient force can be employed by this screw to bring together the palatine processes in any case in which ossification is not a factor; and in cases in which ossification has advanced so far as to prevent immediate approximation, an increased pressure kept up by tightening on the screw will in a short while secure the same result. The fingers alone may be used to tighten the screw, or when the instrument is in position the key which accompanies it can be best employed for this purpose. The two teeth, which are set posteriorly along the inner and upper edge of each lateral plate, are of two-fold value: first, in holding the plates in position by their fixedness in the bony alveolus, and, second, in lessening the injury to the spongy alveolar tissue throughout its entire surface over which the lateral plates are applied. They therefore lessen the general pressure of the entire plate; consequently, what injury the spongy alveolar processes suffer will be mostly at the points where these teeth are fastened.

There is no reason to believe there is any great amount of suffering caused by its use, as its employment, beginning in children as young as 2 days, has not lessened either their general nutrition or development.

1222 Spruce Street.

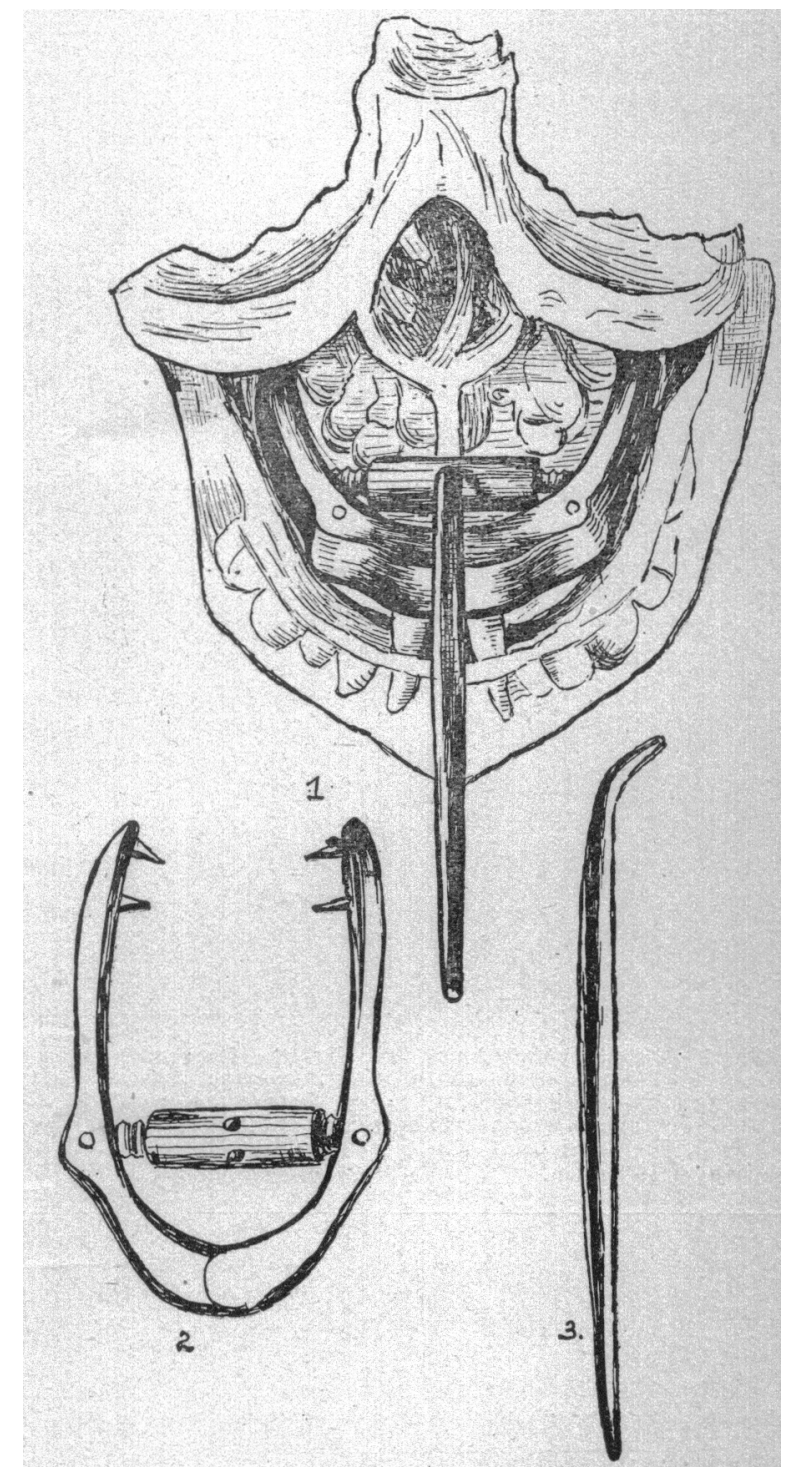

Fig. 1.-Instrument for approximation of the palatine processes in cleft palate in position. Fig. 2.-Instrument partly closed. Fig. 3.-Key.

Specific-Gravity Test for Identification of Criminals.-Debenedetti suggests that important information might be obtained from the individual displacement of water, the special specific gravity, as a means of identifying criminals. He publishes an illustrated communieation on the subject in the Semana Medica, of Buenos Aires, Dec. 31, 1908, p. 1781. Even if the specific gravity of the arm or leg or head were tested alone, possibly sufficient information might be obtained. The water must be always at the same temperature, for which he suggests $37 \mathrm{C}$. $(98 \mathrm{~F}$.), adding that a little salt in the water brings the specific gravity to that of distilled water at $4 \mathrm{C}$. He calls the method "hydrostatic anthropometry;" it is not necessary for ordinary criminals, he remarks, but cases may arise in which further means of identification may be useful. 